\section{RMD Open}

Rheumatic \&

Musculoskeletal Diseases

To cite: Shah K, Paris M, Mellars L, et al. Real-world burden of comorbidities in US patients with psoriatic arthritis. RMD Open 2017;3:e000588. doi:10.1136/ rmdopen-2017-000588

- Prepublication history and additional material for this paper are available online. To view these files, please visit the journal online (http://dx.doi. org/10.1136/rmdopen-2017000588).

Received 25 September 2017 Revised 21 November 2017 Accepted 6 December 2017

\title{
Real-world burden of comorbidities in US patients with psoriatic arthritis
}

\author{
Kamal Shah, ${ }^{1}$ Maria Paris, ${ }^{2}$ Lillian Mellars,${ }^{2}$ Arun Changolkar, ${ }^{1}$ Philip J Mease ${ }^{3}$
}

\section{ABSTRACT}

Objectives We assessed comorbidities associated with psoriatic arthritis in a broad cohort of US-insured adult patients using the Truven Health Analytics MarketScan Database.

Methods Prevalence and incidence rates were assessed for 28 comorbid conditions among adult patients in the MarketScan database with a diagnosis of psoriatic arthritis and having two or more health claims for psoriatic arthritis between 1 July 2008 and 31 July 2015. Findings were compared with those of a similar, previously published analysis of patients with psoriasis.

Results Among a total of 186552 patients with a diagnosis of psoriatic arthritis, 94302 had two or more health claims for psoriatic arthritis during the study period and were included in the comorbidity analysis. The prevalence and incidence rates of the most common comorbidities were $\mathbf{4 7 . 5 \%}$ and $35.0 \%$ for hyperlipidaemia, respectively; $47.3 \%$ and $31.3 \%$ for hypertension; $21.2 \%$ and $15.4 \%$ for depression; $20.2 \%$ and $13.5 \%$ for type 2 diabetes mellitus; and $16.6 \%$ and $12.4 \%$ for fibromyalgia. Patients with psoriatic arthritis had notably higher incidence rates of uveitis, fibromyalgia, osteoporosis, Crohn's disease and non-alcoholic liver disease than patients with psoriasis.

Conclusion This observational retrospective analysis using the MarketScan database provides real-world health claims data on the prevalence and incidence of comorbidities in a large US patient population with psoriatic arthritis. The observed high cardiometabolic comorbidity rates align with those reported in the literature and may help healthcare providers in the comprehensive management of patients with psoriatic arthritis.

\section{INTRODUCTION}

CrossMark

${ }^{1}$ GPS Innovation and GPS US, EMD Serono, Billerica, Massachusetts, USA ${ }^{2}$ Drug Safety, Celgene Corporation, Summit, New Jersey, USA

${ }^{3}$ Swedish Medical Center and University of Washington School of Medicine, Seattle, Washington, USA

Correspondence to Dr Maria Paris; mparis@celgene.com
Psoriatic arthritis is a chronic, inflammatory musculoskeletal disease that has multiple manifestations, including psoriasis. Increasing evidence supports the association between psoriatic arthritis and multiple comorbidities, including obesity, metabolic syndrome, cardiovascular disease, cerebrovascular disease and peripheral vascular disease. ${ }^{1}$ Some studies have provided the rate of selected comorbidities in patients with psoriasis ${ }^{2-4}$; however, fewer studies have been conducted in patients with psoriatic arthritis. In particular, rates of comorbidities in US patients with psoriatic arthritis have not been fully characterised.

\section{Key messages}

What is already known about this subject?

- Psoriatic arthritis is associated with comorbidities that can influence treatment decisions and management strategies.

- Prevalence and incidence rates of comorbidities associated with psoriatic arthritis have not been fully characterised.

What does this study add?

- This observational retrospective analysis using the MarketScan database provides real-world health claims data on the prevalence and incidence of comorbidities in a large US patient population with psoriatic arthritis.

How might this impact on clinical practice?

- Understanding the prevalence and incidence of comorbidities can aid healthcare professionals in the comprehensive management of patients with psoriatic arthritis.

Comorbidity rates may be determined using various approaches, including randomised trials or studies using postmarketing surveillance, registry or medical claims data; each approach has its strengths and weaknesses. The study populations included in randomised clinical trials often do not represent the broader, real-world populations. ${ }^{5}$ Postmarketing surveillance data consist of spontaneously reported adverse events that are often affected by under-reporting bias. $^{6-8}$ Patient registries address some of these issues, providing more robust information, but they often capture data from studies with limited sample sizes and study durations. ${ }^{9}$

Medical insurance claims databases can be used to study large populations of patients afflicted with a specific disease and provide an effective means to assess comorbidity-related event rates in real-world populations. This study used a large insurance claims database to gain an understanding of the rate of comorbidities in a broad population-based cohort of adult patients with psoriatic arthritis. 


\section{METHODS}

\section{Data source}

Using the Truven Health Analytics MarketScan Database (Truven Health Analytics, an IBM company, Ann Arbor, Michigan, USA), health insurance claims from insured individuals were examined from 1 July 2008 through 31 July 2015. The database contains US administrative claims for commercially insured, working-age adults and their dependents, as well as individuals with Medicare supplemental insurance paid for by employers. Employer-provided data allow for tracking across health plans and, overall, contain administrative claims and eligibility records for approximately 230 million patient-lives since $1995 .{ }^{10}$ Enrolment records contain demographic information, including age, sex and geographical region. Medical claims files include inpatient, outpatient, facility and service claims records. The database is compliant with the Health Insurance Portability and Accountability Act and contains synthetic identifiers to protect the privacy of all patients and data contributors.

\section{Study population}

Adult patients ( $\geq 18$ years of age) who were diagnosed with psoriatic arthritis using the International Classification of Diseases, 9th Revision, Clinical Modification (ICD-9-CM) code 696.0x, ${ }^{11}$ with the first diagnosis claim between 1 July 2008 and 30 June 2014 and at least one additional psoriatic arthritis-related claim on or before 31 July 2015, were included in the study. The first diagnosis claim was set as the index date. Patients meeting the inclusion criteria are referred to as the psoriatic arthritis population. In addition, patients with psoriatic arthritis who met a minimum continuous health plan enrolment from 6 months before the index date through 6 months after the index date were selected and are referred to as the continuously enrolled population. Patients were studied until loss of insurance eligibility or the end of the study period.

\section{Study outcomes}

The 28 outcomes chosen for this study reflect a broad spectrum of comorbid conditions (table 1). The ICD-9-CM codes chosen for the study outcomes were based on medical judgement or had been used in the literature previously. The ICD-9-CM codes for acute myocardial infarction (MI), ${ }^{12}$ stroke $^{13}$ and depression ${ }^{14}$ have been validated, and the ICD-9-CM codes for infections have been used previously. ${ }^{15}$ Acute MI was determined using the primary diagnosis code for inpatient diagnoses. Stroke and infections were determined based on any inpatient diagnosis. Other outcomes were determined based on at least one diagnosis in any claim (see online supplementary table 1 for a complete list of codes and diagnosis claims considered). ${ }^{12-17}$

\section{Analysis}

Continuous variables were summarised using mean and $\mathrm{SD}$, and the discrete data were summarised using counts
Table 1 Comorbid conditions selected for outcomes in patients with psoriatic arthritis

\begin{tabular}{|c|c|}
\hline \multicolumn{2}{|l|}{ Comorbid conditions } \\
\hline Acute myocardial infarction & Ischaemic stroke \\
\hline Atherosclerosis & Non-melanoma skin cancer \\
\hline Cardiac dysrhythmias & Non-alcoholic liver disease \\
\hline Cerebrovascular diseases & Major depression \\
\hline Chronic renal insufficiency & $\begin{array}{l}\text { Major depression, suicide and } \\
\text { suicidal ideation }\end{array}$ \\
\hline Crohn's disease & Osteoporosis \\
\hline Congestive heart failure & Obesity \\
\hline Depression & Peripheral vascular disease \\
\hline Fibromyalgia & $\begin{array}{l}\text { Solid tumours (including } \\
\text { melanoma) }\end{array}$ \\
\hline Gout & Stroke \\
\hline $\begin{array}{l}\text { Haematological } \\
\text { malignancies }\end{array}$ & Type 2 diabetes mellitus \\
\hline Hyperlipidaemia & Ulcerative colitis \\
\hline Hypertension & Uveitis \\
\hline \multicolumn{2}{|l|}{ Infections } \\
\hline Ischaemic heart disease & \\
\hline
\end{tabular}

and percentages. Estimates for prevalence (\%) and incidence $(\%)$ rates of the comorbidities were determined. Prevalence was defined as the proportion of occurrences of the specific comorbidity-related event during the study period divided by the total population. Incidence was defined as the proportion of new occurrences of the specific comorbidity divided by the population at risk for developing the comorbidity after the index date (ie, patients who had a claim for the comorbidity before the index date were excluded). In addition, the incidence (new occurrences of the specific comorbidity) per patient time (presented as per 100 patient-years) is provided, where patient time is the total years at risk that all patients contributed to the study. Included here are selected findings from an identically designed analysis of the MarketScan database performed in patients with psoriasis (identified through ICD-9-CM code 696.1) ) $^{18} 19$ with the same index date and inclusion criteria that were used to identify patients with psoriatic arthritis in the current analysis. Portions of the findings in patients with psoriasis have been published. ${ }^{19}$ The ratio of the incidence rates per 100 patient-years for psoriasis ${ }^{19}$ and psoriatic arthritis was determined, along with the 95\% confidence limits established using the Poisson distribution.

\section{RESULTS}

\section{Patients}

The MarketScan database had 186552 patients with at least one claim for a diagnosis of psoriatic arthritis between 1 January 2008 and 31 December 2014. Of these, 94302 patients qualified for inclusion in the psoriatic 
Table 2 Therapeutic usage ${ }^{*}$ among patients with psoriatic arthritis by drug class

\begin{tabular}{lll}
\hline & \multicolumn{2}{l}{$\begin{array}{l}\text { Psoriatic arthritis population } \\
(\mathbf{n = 9 4 3 0 2 )}\end{array}$} \\
\cline { 2 - 3 } Drug classification & $\mathbf{n} †$ & $\%$ \\
\hline Biologics $\ddagger$ & 31308 & 33.20 \\
DMARDs§ & 38099 & 40.40 \\
NSAIDs & 43194 & 45.80 \\
Steroids & 56915 & 60.35 \\
\hline
\end{tabular}

*Treatments used on or after the index date (first diagnosis of psoriatic arthritis).

†Number of patients who received one or more therapies. Patients who received more than one therapy are included for each therapy class received.

$\ddagger$ Also known as biologic DMARDs.

§Include conventional oral DMARDs, including conventional synthetic DMARDs and the targeted synthetic DMARDs tofacitinib and apremilast.

DMARDs, disease-modifying antirheumatic drugs; NSAIDs, nonsteroidal anti-inflammatory drugs.

arthritis population, and 47438 patients met the continuous enrolment criteria. In the psoriatic arthritis population, $53.6 \%$ of the patients were female and the median age was 52 years. In each cohort, the numbers of patients diagnosed each year were similar, except for 2008 and 2014, which had fewer patients because the index date for the cohort was selected to allow the potential of 6 months of data before and after the index date (see online supplementary table 2 for demographic characteristics). The total follow-up for the psoriatic arthritis population was 150626 patient-years, which represents an average of approximately 1.5 years per patient. Approximately one-third of patients were taking biologics at baseline, and $40 \%$ and $46 \%$ of patients were taking disease-modifying antirheumatic drugs and non-steroidal anti-inflammatory drugs, respectively (table 2 ).

\section{Comorbidities}

The prevalence and incidence rates of the selected comorbidities in each cohort of patients with psoriatic arthritis are shown in table 3. Among patients in the psoriatic arthritis population, the most prevalent comorbidities ( $>10 \%$ of patients) were hyperlipidaemia (47.5\%), hypertension (47.3\%), depression (21.2\%), type 2 diabetes mellitus $(20.2 \%)$, fibromyalgia $(16.6 \%)$, obesity $(16.5 \%)$, ischaemic heart disease $(11.6 \%)$ and cardiac dysrhythmias $(10.4 \%)$. Incidence rates and incidence rates per 100 patient-years exhibited patterns of frequency ranking that were closely similar to prevalence rates. Table 4 presents the prevalence rates of comorbidities related to metabolic syndrome (eg, hyperlipidaemia, hypertension, type 2 diabetes mellitus, obesity) as observed currently and side by side with those in previously published reports, ${ }^{20-22}$ as well as in the general US adult population. ${ }^{23-26}$ Prevalence rates for these conditions were generally similar to prior reports in patients with psoriatic arthritis, except for obesity, which had a somewhat lower prevalence among the current patient cohort. Comorbidities related to metabolic syndrome were generally greater in the current cohort and in prior reports than in the general US population, with the exception of obesity, which is estimated to affect $36.5 \%$ of US adults. ${ }^{25}$

\section{Comparison with patients with psoriasis}

Table 5 shows the comparison of the incidence rates of comorbidities per 100 patient-years for patients with psoriatic arthritis and an identically designed analysis of MarketScan data for patients with psoriasis. ${ }^{19}$ Incidence rates of fibromyalgia, gout and ulcerative colitis per 100 patient-years in patients with psoriasis were not included in the MarketScan psoriasis analysis publication. However, to provide comparison with all the comorbidities identified in the psoriatic arthritis analysis, we also examined and report here the incidence rates of these additional comorbidities in the psoriasis population (table 5). Compared with patients with psoriasis, those with psoriatic arthritis exhibited a higher incidence rate of nearly all comorbidities examined. Based on the analysis of the psoriatic arthritis population, the greatest disparities in incidence rate per 100 patient-years among patients with psoriatic arthritis versus patients with psoriasis were seen for uveitis (103\% increase), fibromyalgia (77\% increase), osteoporosis (75\% increase), Crohn's disease (58\% increase) and non-alcoholic liver disease (50\% increase) (table 5).

\section{DISCUSSION}

The psoriatic disease process, with signs and symptoms that may involve joints (psoriatic arthritis) and skin (psoriasis), is driven by chronic, immune-mediated, systemic inflammation. ${ }^{3} 27$ Because underlying inflammatory processes may increase the risk of comorbid conditions, ${ }^{3}$ a better understanding of that risk may aid physicians in managing patients with psoriatic arthritis and psoriasis. In this study of a very large, population-based cohort of patients with psoriatic arthritis, the most common comorbidities were hyperlipidaemia, hypertension, depression, type 2 diabetes mellitus, obesity, ischaemic heart disease, fibromyalgia and cardiac dysrhythmias. These results in a US-insured population are comparable with previously published literature in patients with psoriatic arthritis and select comorbidities examined in other US and Canadian populations using other methodology. ${ }^{20-22}$

In patients with psoriatic arthritis, many of the most common comorbidities identified in the current analysis are related to metabolic syndrome, including hyperlipidaemia, hypertension, type 2 diabetes mellitus and obesity. The heightened risk of metabolic syndrome has been identified in patients with psoriatic disease, ${ }^{428}$ and metabolic syndrome, in turn, is a known risk factor for heart disease and stroke. ${ }^{29}$ The rates of these comorbidities have also been studied by others (table 4$){ }^{20-22}$ Generally, prevalence magnitudes are similar among the 
Table 3 Prevalence and incidence rates of comorbidities observed among patients with psoriatic arthritis

Psoriatic

arthritis

population

( $\mathrm{n}=94302)$
Continuously enrolled Psoriatic arthritis population population* $(n=47438) \quad(n=94302)$

\begin{tabular}{|c|c|c|c|c|c|c|}
\hline \multirow{2}{*}{$\begin{array}{l}\text { Comorbid condition† } \\
\text { Hyperlipidaemiaๆ }\end{array}$} & \multicolumn{2}{|c|}{ Prevalenceł, n (\%) } & \multirow{2}{*}{$\begin{array}{l}\text { Incidence§, } \mathbf{n} \text { (\%) } \\
23156(35.0)\end{array}$} & \multirow{2}{*}{ patient-years } & \multirow{2}{*}{$\begin{array}{l}\text { (\%) } \\
8202(30.02)\end{array}$} & \multirow{2}{*}{ patient-years } \\
\hline & $44768(47.47)$ & $23811(50.19)$ & & & & \\
\hline Hypertensionף & $44583(47.28)$ & 23447 (49.43) & $20599(31.25)$ & 23.91 & $6773(24.25)$ & 17.15 \\
\hline Depression & $19995(21.2)$ & $10656(22.46)$ & $12853(15.44)$ & 10.16 & $5671(14.34)$ & 9.50 \\
\hline Type 2 diabetes mellitus & $19037(20.19)$ & $10036(21.16)$ & $11794(13.49)$ & 8.72 & $5558(13.14)$ & 8.57 \\
\hline Fibromyalgia & $15635(16.58)$ & $8306(17.51)$ & $10453(12.36)$ & 8.07 & 4848 (11.96) & 7.94 \\
\hline Obesity & $15510(16.45)$ & $8331(17.56)$ & $8742(10.65)$ & 7.05 & 3425 (8.69) & 5.78 \\
\hline Ischaemic heart disease & $10918(11.58)$ & $6005(12.66)$ & $7256(8.10)$ & 5.19 & $3704(8.44)$ & 5.54 \\
\hline Cardiac dysrhythmias $\|$ & $9756(10.35)$ & $5510(11.62)$ & $6819(7.73)$ & 5.01 & $3022(7.05)$ & 4.66 \\
\hline Osteoporosis & $8802(9.33)$ & $4665(9.83)$ & $6415(7.16)$ & 4.63 & $3017(6.85)$ & 4.56 \\
\hline $\begin{array}{l}\text { Peripheral vascular } \\
\text { disease }\end{array}$ & $7298(7.74)$ & $4202(8.86)$ & $6275(6.91)$ & 4.40 & $3352(7.49)$ & 4.94 \\
\hline Infections ${ }^{\star \star}$ & $7159(7.59)$ & $4058(8.55)$ & $5656(6.26)$ & 3.98 & 2967 (6.66) & 4.37 \\
\hline Cerebrovascular disease & $6903(7.32)$ & $3953(8.33)$ & $5478(6.02)$ & 3.84 & $2829(6.31)$ & 4.14 \\
\hline Major depression & $6686(7.09)$ & $3655(7.7)$ & $4730(5.14)$ & 3.27 & $2391(5.23)$ & 3.43 \\
\hline $\begin{array}{l}\text { Solid tumours, including } \\
\text { melanoma }\end{array}$ & $5963(6.32)$ & $3340(7.04)$ & $4343(4.80)$ & 3.04 & $2098(4.69)$ & 3.08 \\
\hline Gout & $5673(6.02)$ & $3278(6.91)$ & $3757(4.12)$ & 2.62 & $1789(3.97)$ & 2.60 \\
\hline $\begin{array}{l}\text { Non-alcoholic liver } \\
\text { disease }\end{array}$ & $5440(5.77)$ & $2930(6.18)$ & $3587(3.88)$ & 2.46 & $1780(3.86)$ & 2.53 \\
\hline Chronic renal insufficiency & $4867(5.16)$ & $2637(5.56)$ & $3466(3.85)$ & 2.44 & $1777(4.00)$ & 2.63 \\
\hline $\begin{array}{l}\text { Non-melanoma skin } \\
\text { cancers }\end{array}$ & 3707 (3.93) & $2069(4.36)$ & $3041(3.29)$ & 2.08 & $1548(3.36)$ & 2.21 \\
\hline Congestive heart failure & 3698 (3.92) & $2157(4.55)$ & $2852(3.07)$ & 1.94 & 1539 (3.32) & 2.18 \\
\hline Atherosclerosis & 3355 (3.56) & $1942(4.09)$ & $2803(3.02)$ & 1.91 & $1524(3.3)$ & 2.16 \\
\hline Uveitis & $1466(1.55)$ & $790(1.67)$ & $949(1.02)$ & 0.64 & $424(0.91)$ & 0.59 \\
\hline Ulcerative colitis & $1206(1.28)$ & $656(1.38)$ & $801(0.86)$ & 0.54 & $365(0.778)$ & 0.51 \\
\hline $\begin{array}{l}\text { Haematological } \\
\text { malignancies }\end{array}$ & $1079(1.14)$ & $604(1.27)$ & $771(0.82)$ & 0.52 & $412(0.88)$ & 0.57 \\
\hline Crohn's disease & $1070(1.13)$ & $604(1.27)$ & $626(0.67)$ & 0.42 & $303(0.64)$ & 0.42 \\
\hline $\begin{array}{l}\text { Acute myocardial } \\
\text { infarction** } † \dagger\end{array}$ & $524(0.56)$ & $292(0.62)$ & $506(0.54)$ & 0.34 & $281(0.59)$ & 0.39 \\
\hline $\begin{array}{l}\text { Suicide and suicidal } \\
\text { ideation }\end{array}$ & $453(0.48)$ & $253(0.53)$ & $434(0.46)$ & 0.29 & $245(0.52)$ & 0.34 \\
\hline Any stroke $e^{\star \star} \neq \ddagger$ & $445(0.47)$ & $255(0.54)$ & $420(0.45)$ & 0.28 & $234(0.49)$ & 0.32 \\
\hline Ischaemic stroke ${ }^{\star \star} \neq \ddagger$ & $342(0.36)$ & $198(0.42)$ & $332(0.35)$ & 0.22 & $189(0.40)$ & 0.26 \\
\hline
\end{tabular}

${ }^{*}$ Continuous enrolment with a minimum of 12 months: 6 months before the index date and 6 months after the index date.

†Includes all claims and any diagnosis field unless specified otherwise.

$\ddagger$ Prevalence is the proportion of occurrences for the specific comorbidity during the study period divided by the total population.

§Incidence is the proportion of new occurrences of the specific comorbidity divided by the population at risk for developing the comorbidity after the index date (ie, patients who had a claim for the comorbidity before the index date are excluded).

१Medical conditions that can be associated with an increased risk of major adverse cardiac event.

${ }^{* \star}$ Includes only serious medical conditions (ie, those with an inpatient diagnosis).

$\dagger †$ Acute myocardial infarction was based on the inpatient primary discharge diagnosis claims (ie, the primary discharge diagnosis).

$\ddagger \ddagger$ Cases that likely represent a major adverse cardiac event.

reported analyses, although the results using the largest populations and the MarketScan database tend to have the highest prevalence rates. Compared with the general US adult population, prevalence of these comorbidities is markedly greater in patients with psoriatic arthritis (table 4). For example, diabetes mellitus is estimated to affect $9.4 \%$ of the general US population, and $90 \%-95 \%$ of these cases comprise type 2 diabetes mellitus. ${ }^{23}$ In the 
Table 4 Prevalence of metabolic syndrome comorbidity in patients with psoriatic arthritis: comparison with literature and the general US population

\begin{tabular}{|c|c|c|c|c|c|c|c|}
\hline \multirow[b]{2}{*}{ Outcome, \% } & \multirow[b]{2}{*}{$\begin{array}{l}\text { Continuously } \\
\text { enrolled } \\
\text { population }\end{array}$} & \multicolumn{2}{|c|}{ Merola et $a l^{31 *}$} & \multirow[b]{2}{*}{$\begin{array}{l}\text { Han et } \\
\mathrm{al}^{20} \mathrm{t}\end{array}$} & \multirow[b]{2}{*}{$\begin{array}{l}\text { Feldman } \\
\text { et } a^{21} \ddagger\end{array}$} & \multirow[b]{2}{*}{ Husted et $a l^{22} \S$} & \multirow[b]{2}{*}{$\begin{array}{l}\text { US general } \\
\text { population }\end{array}$} \\
\hline & & $\begin{array}{l}\text { Psoriatic } \\
\text { arthritis and } \\
\text { moderate } \\
\text { to severe } \\
\text { psoriasis }\end{array}$ & $\begin{array}{l}\text { Psoriatic } \\
\text { arthritis/ } \\
\text { minimal skin }\end{array}$ & & & & \\
\hline Hyperlipidaemiaๆ & 47.5 & 55.3 & 53.8 & 27.8 & 34.6 & 20.7 & 12.1 \\
\hline Hypertension & 47.3 & 51.0 & 49.7 & 28.5 & 35.8 & 37.1 & 25.0 \\
\hline $\begin{array}{l}\text { Type } 2 \text { diabetes } \\
\text { mellitus }\end{array}$ & 20.2 & 21.2 & 20.0 & 11.3 & & 12.0 & 9.4 \\
\hline Obesity & 16.5 & 21.5 & 15.9 & NA & & $\begin{array}{l}30(\mathrm{BMI} \geq 30 \mathrm{~kg} / \\
\left.\mathrm{m}^{2}\right)\end{array}$ & 36.5 \\
\hline
\end{tabular}

*Merola et al reported on two groups of patients with psoriatic arthritis selected from the MarketScan database: patients with moderate to severe psoriasis and those with only minimal skin involvement.

†Han et al reported on 3066 patients with psoriatic arthritis who were selected from the PharMetrics' Patient-Centric Database, which contains fully adjudicated medical service claims from health plans across the USA. Age-adjusted and sexadjusted.

¥Feldman et al reported on 1230 US patients with psoriasis and comorbid psoriatic arthritis selected from the OptumHealth Reporting and Insights claims database.

§Husted et al reported on 611 patients with psoriatic arthritis selected from the University of Toronto Psoriatic Arthritis Clinic. १(Merola et al reported on dyslipidaemia and diabetes versus type 2 diabetes mellitus specifically.

BMI, body mass index; NA, not applicable.

current study, $20.2 \%$ of patients with psoriatic arthritis had type 2 diabetes mellitus. Likewise, in Canadian patients with psoriatic arthritis, the prevalence of diabetes mellitus has been found to be $43 \%$ higher than in the general population. ${ }^{30}$ The notable exception is obesity, which is estimated to affect $36.5 \%$ of US adults, ${ }^{25}$ but in the current cohort was identified in $16.5 \%$ of patients.

The prevalence of obesity may be difficult to study in health claims databases. In our analysis and in the analysis reported by Merola et $a l^{31}{ }^{31}$ both using the MarketScan database, the results for obesity were lower than that reported elsewhere. ${ }^{20-22}$ In patients selected from the Toronto and Vancouver sites in the International Psoriasis and Arthritis Research Team database, the proportions of patients with obesity $\left(\geq 30 \mathrm{~kg} / \mathrm{m}^{2}\right)$ in the psoriatic arthritis and general populations were $37 \%$ and $18 \%$, respectively. ${ }^{32}$ Husted and colleagues ${ }^{22}$ reported an obesity rate of $30 \%$ in patients with psoriatic arthritis. Physicians may not include obesity as a diagnosis because it most likely is not the reason patients sought or paid for medical services at that visit.

The prevalence rate of acute MI in the psoriatic arthritis population in this study was $0.56 \%$, and the incidence per 100 patient-years was 0.34 ; by contrast, the incidence of acute MI per 100 patient-years was greater among patients with psoriasis $(0.49) .{ }^{19}$ In both psoriatic populations, the incidence of acute MI is greater than in the general US population $(0.17 \%) \cdot{ }^{33}$ Information reported in the literature is limited regarding the prevalence of MI in patients with psoriatic arthritis. In an analysis of the University of Toronto psoriatic arthritis clinical database, Gladman and colleagues ${ }^{34}$ reported 50 MIs in 648 registered patients $(7.7 \%)$, including events before study entry. Feldman and coworkers ${ }^{21}$ reported the prevalence of acute MI in $0.57 \%(7 / 1230)$ of patients with psoriasis and comorbid psoriatic arthritis. In a prospective cohort study of patients with psoriatic arthritis, Eder et $a l^{35}$ concluded that the level of disease activity and extent of systemic inflammation were independent factors of cardiovascular events, in addition to traditional cardiovascular risk factors. It has been reported in the literature that the use of tumour necrosis factor inhibitors may be associated with a reduced risk of adverse cardiovascular events, although the authors recognised that well-controlled randomised studies would be needed to evaluate the exact cardiovascular effects. ${ }^{36}$ It is interesting to note that, in the current analysis, use of biologics was greater in the psoriatic arthritis population than in the psoriasis population $^{19}$ (table 2$)$.

In this study, the prevalence of cerebrovascular disease in the psoriatic arthritis population was $7.3 \%$, and the prevalence of any stroke was $0.47 \%$. Merola et $a b^{31}$ reported the prevalence of cerebrovascular disease ranged from $6.2 \%$ to $6.7 \%$ for patients with psoriatic arthritis and psoriasis, but stroke was not mentioned specifically. Similar to other comorbid conditions, the prevalence of stroke in patients with psoriatic arthritis and psoriasis was higher in our study than in the general US population $(2.5 \%){ }^{24}$

In the analysis reported here, the prevalence of depression in the psoriatic arthritis population was $21 \%$, which is greater than in the US general population $(7.6 \%),{ }^{37}$ but similar to that reported by Merola et $a \hat{l}^{11}$ in patients with psoriatic arthritis and moderate to 
Table 5 Comparison of incidence rates of comorbidities observed among patients with psoriatic arthritis and psoriasis

Full population

(incidence per 100 patient-years)

\section{Psoriatic}

Comorbidity

Hyperlipidaemia

arthritis

( $n=94302$ )

Hypertension

27.11

Depression

Obesity

Fibromyalgia†

Type 2 diabetes

mellitus

\begin{tabular}{|c|c|c|c|c|c|c|}
\hline Cardiac dysrhythmias & 5.19 & 4.47 & $1.16(1.13$ to 1.19$)$ & 5.54 & 4.65 & $1.19(1.15$ to 1.23$)$ \\
\hline $\begin{array}{l}\text { Ischaemic heart } \\
\text { disease }\end{array}$ & 5.01 & 4.06 & 1.23 (1.20 to 1.27$)$ & 4.66 & 3.90 & $1.20(1.15$ to 1.24$)$ \\
\hline Infections & 4.40 & 3.55 & 1.24 (1.21 to 1.27$)$ & 4.94 & 3.80 & $1.30(1.25$ to 1.35$)$ \\
\hline $\begin{array}{l}\text { Peripheral vascular } \\
\text { disease }\end{array}$ & 3.98 & 3.42 & $1.16(1.13$ to 1.20$)$ & 4.37 & 3.62 & 1.21 (1.16 to 1.25$)$ \\
\hline $\begin{array}{l}\text { Non-alcoholic liver } \\
\text { disease }\end{array}$ & 3.27 & 2.18 & 1.50 (1.45 to 1.55$)$ & 3.43 & 2.13 & 1.61 (1.54 to 1.68$)$ \\
\hline Major depression & 3.04 & 2.26 & 1.35 (1.30 to 1.39$)$ & 3.08 & 2.21 & 1.39 (1.33 to 1.46$)$ \\
\hline $\begin{array}{l}\text { Solid tumours, } \\
\text { including melanoma }\end{array}$ & 2.62 & 2.53 & 1.03 (1.00 to 1.07$)$ & 2.60 & 2.49 & 1.05 (1.00 to 1.10$)$ \\
\hline $\begin{array}{l}\text { Non-melanoma skin } \\
\text { cancers }\end{array}$ & 2.08 & 2.35 & 0.88 (0.85 to 0.92$)$ & 2.21 & 2.51 & 0.88 (0.83 to 0.93$)$ \\
\hline $\begin{array}{l}\text { Congestive heart } \\
\text { failure }\end{array}$ & 1.94 & 1.66 & 1.17 (1.12 to 1.22$)$ & 2.18 & 1.78 & $1.22(1.16$ to 1.29$)$ \\
\hline Atherosclerosis & 1.91 & 1.87 & 1.02 (0.98 to 1.06$)$ & 2.16 & 2.02 & 1.07 (1.01 to 1.13$)$ \\
\hline Uveitis & 0.64 & 0.32 & 2.03 (1.88 to 2.19$)$ & 0.59 & 0.32 & 1.86 (1.67 to 2.07 ) \\
\hline Ulcerative colitis $†$ & 0.54 & 0.43 & 1.26 (1.17 to 1.36$)$ & 0.51 & 0.41 & 1.24 (1.11 to 1.39$)$ \\
\hline $\begin{array}{l}\text { Haematological } \\
\text { malignancies }\end{array}$ & 0.52 & 0.45 & 1.14 (1.05 to 1.23$)$ & 0.57 & 0.46 & 1.25 (1.12 to 1.39$)$ \\
\hline Crohn's disease & 0.42 & 0.26 & 1.58 (1.45 to 1.73$)$ & 0.42 & 0.24 & 1.75 (1.55 to 1.99$)$ \\
\hline
\end{tabular}

${ }^{*}$ Ratio is psoriatic arthritis/psoriasis incidence rates, where a ratio $>1$ indicates that patients with psoriatic arthritis have greater incidence. †Gout, fibromyalgia and ulcerative colitis rates are not reported in the psoriasis MarketScan publication. ${ }^{19}$

severe psoriasis $(23.2 \%)$ and in patients with psoriatic arthritis and minimal skin involvement $(20.1 \%)$. The prevalence of major depression in our study ranged from $7 \%$ to $8 \%$. McDonough and colleagues ${ }^{38}$ also observed a similar prevalence of depression among 306 patients with psoriatic arthritis attending psoriatic arthritis and dermatology clinics at Toronto Western Hospital.

\section{Continuously enrolled population} (incidence per 100 patient-years)

Psoriatic arthritis Psoriasis ${ }^{19}$

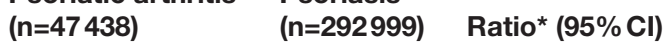

$21.31 \quad 18.81 \quad 1.13(1.11$ to 1.16$)$

$17.15 \quad 13.49 \quad 1.27(1.24$ to 1.30$)$

$9.50 \quad 7.36 \quad 1.29(1.25$ to 1.33$)$

$8.57 \quad 6.81 \quad 1.26$ (1.22 to 1.30$)$

$\begin{array}{lll}7.94 & 4.58 & 1.73(1.68 \text { to } 1.79)\end{array}$

$5.78 \quad 4.59 \quad 1.26(1.21$ to 1.30$)$


respectively. A prospective study by Rohekar et $a l,{ }^{39}$ which reported the results from an additional 14-year analysis of the University of Toronto psoriatic arthritis clinical database, found that malignancy developed in 68 of 665 $(10.2 \%)$ patients with psoriatic arthritis. Feldman and coworkers reported a prevalence of $2.2 \%(27 / 1230)$ for NMSC and 2.0\% (25/1230) for other malignancies. ${ }^{21}$ In a study of 2970 patients with psoriatic arthritis included in the Consortium of Rheumatology Researchers of North America registry, the adjudicated incidence rates of NMSC, solid tumours and haematological tumours were $0.5 \% \quad(15 / 2970 ; 0.21$ per 100 patient-years $)$, $0.67 \%(20 / 2970 ; 0.28$ per 100 patient-years) and $0.17 \%$ (5/2970; 0.07 per 100 patient-years), respectively. ${ }^{40}$ The annual incidence of any type of malignancy in the general US population is estimated at $0.44 \% .^{41}$ Such findings suggest that the incidence of malignancy varies widely and depends on the approach to detecting and verifying such events. Differences in reported incidences may be due to differences in sample size, unknown registry inclusion/exclusion criteria, differences in provider type (eg, university-affiliated clinics vs all community practitioners) and coding inconsistencies. Notably, the lowest reported malignancy incidence rate in patients with psoriatic arthritis was described when events were adjudicated, perhaps indicating that accurate detection requires clinical verification and validation with a larger cohort. Given these discrepancies, further validation to identify true prevalence or incidence rates of malignancies in psoriatic arthritis is needed.

The prevalence of fibromyalgia (16.6\%) in our study aligns with the study by Brikman and colleagues. ${ }^{42}$

Notable differences in comorbidity rates between patients with psoriatic arthritis in this study $(\mathrm{n}=94302)$ and patients with psoriasis in an identically designed analysis of MarketScan data $(\mathrm{n}=469097)^{19}$ have been observed for depression, type 2 diabetes mellitus, osteoporosis, serious infections, NMSC, suicide and suicidal ideation, fibromyalgia, ulcerative colitis, gout, non-alcoholic liver disease, acute MI, uveitis and major depression. Despite the greater published focus and research on depression associated with psoriasis, the higher rate of depression in patients with psoriatic arthritis compared with psoriasis based on the current analysis was also observed by McDonough and coworkers. ${ }^{38}$

Except for acute MI and NMSC, patients with psoriatic arthritis had higher rates of comorbidities than patients with psoriasis, although it is important to recognise that within the psoriasis population, some of the patients may also have had psoriatic arthritis. ${ }^{19} \mathrm{~A}$ potential factor associated with these differences may be the different treatment paradigms for the two conditions. Lim and Stern studied the relationship between skin cancer and ultraviolet B (UVB) therapy in a safety study of psoralen plus ultraviolet A therapy, concluding that for patients with high UVB exposure levels, UVB confers a modest increase in NMSC risk. ${ }^{43}$ Additional research is needed to evaluate whether psoriatic arthritis is an independent risk factor for acute MI and NMSC comorbidities.

\section{Limitations}

While large retrospective databases such as the one used for the current analysis have broad cohorts of patients representing a real-world population, limitations must be considered; these limitations have been previously published. ${ }^{44}$ The selected populations may not be reflective of the age distribution of the psoriatic arthritis population because the MarketScan database contains only claims from a US commercially insured population and healthcare claims from individuals with Medicare supplemental insurance paid for by employers. In addition, the psoriasis population may include patients who also have claims for psoriatic arthritis. The claim information could be subject to misclassifications, as the primary purpose is reimbursement, leading to potentially inaccurate identification of patients' conditions. There is no single correct definition of an outcome (ICD-9-CM codes used), and each definition has its own pros and cons, with some typically more sensitive or more specific than others. Some differences in the prevalence rates in our study compared with research conducted by others most likely are a result of differences in the study design, that is, selection of ICD-9-CM codes, study period and selection of diagnosis fields. The comparison of the comorbidity rates with the general US population based on references is a limitation of the analysis; it would have been best to have selected a control group from the MarketScan database. In the future, a database that coordinates medical records, such as the UK Clinical Practice Research Datalink data set, which contains high-quality longitudinal person-specific records that enable drug safety and outcomes research, may become available in the USA and would provide greater opportunities for outcome research in large population-based studies.

\section{Summary}

This observational retrospective analysis of a large administrative health claims database assessed the real-world prevalence and incidence of comorbidities in a large cohort of patients diagnosed with psoriatic arthritis in the USA. The results are important, as information in the literature is limited regarding the prevalence and incidence of comorbidities in the US patient population with psoriatic arthritis, and realworld evidence will be helpful to healthcare providers who manage the care of these patients. These findings, which are consistent with other reports in the literature, demonstrate that a substantial proportion of patients with psoriatic arthritis have comorbid conditions that may confer additional health risks and may influence the choice of treatment.

\section{CONCLUSION}

Health claims databases provide a unique opportunity and are a valuable resource for estimating the 
prevalence and incidence of comorbid diseases in large, diverse patient populations. Our study highlights the need to assess possible comorbid conditions in patients with psoriatic disease and to incorporate that information into treatment considerations and outcomes.

Contributors KS, MP, LM, AC and PJM conceived and designed the experiments. $\mathrm{KS}, \mathrm{LM}, \mathrm{AC}$ and PJM were involved in the acquisition, analysis and interpretation of the data. All authors were involved in drafting the article or revising it critically for important intellectual content, and all authors approved the final version to be submitted for publication.

Funding This study was sponsored by Celgene Corporation. The authors received editorial support in the preparation of the manuscript from Peloton Advantage, funded by Celgene Corporation. The authors, however, wrote, directed and are fully responsible for all content and editorial decisions related to the development of the manuscript.

Competing interests KS was an employee of Celgene Corporation at the time of study conduct and had access to stocks, stock options and restricted stock units in Celgene Corporation. MP is an employee of Celgene Corporation. LM and AC were contractors for Celgene Corporation at the time of study conduct. PJM has received grant/research support and has served as a consultant for AbbVie, Amgen, Biogen Idec, Bristol-Myers Squibb, Celgene Corporation, Janssen Pharmaceutical, Eli Lilly and Company, Novartis Pharmaceuticals, Pfizer, Sun Pharmaceutical and UCB, and has served on a speakers bureau for AbbVie, Amgen, Biogen Idec, Bristol-Myers Squibb, Celgene Corporation, Genentech, Janssen Pharmaceutical, Eli Lilly and Company, Pfizer and UCB.

Provenance and peer review Not commissioned; externally peer reviewed.

Data sharing statement All authors had full access to all the data, and the data are available upon request.

Open Access This is an Open Access article distributed in accordance with the terms of the Creative Commons Attribution (CC BY 4.0) license, which permits others to distribute, remix, adapt and build upon this work, for commercial use provided the original work is properly cited. See: http://creativecommons.org/ licenses/by/4.0/

(c) Article author(s) (or their employer(s) unless otherwise stated in the text of the article) 2017. All rights reserved. No commercial use is permitted unless otherwise expressly granted.

\section{REFERENCES}

1. Ogdie A, Schwartzman S, Husni ME. Recognizing and managing comorbidities in psoriatic arthritis. Curr Opin Rheumatol 2015;27:118-26

2. Oliveira MF, Rocha BO, Duarte GV. Psoriasis: classical and emerging comorbidities. An Bras Dermatol 2015;90:9-20.

3. Davidovici BB, Sattar N, Prinz J, et al. Psoriasis and systemic inflammatory diseases: potential mechanistic links between skin disease and co-morbid conditions. J Invest Dermatol 2010;130:1785-96.

4. Gelfand JM, Yeung $\mathrm{H}$. Metabolic syndrome in patients with psoriatic disease. J Rheumatol Suppl 2012;89:24-8.

5. Kennedy-Martin T, Curtis S, Faries D, et al. A literature review on the representativeness of randomized controlled trial samples and implications for the external validity of trial results. Trials 2015;16:495

6. Alemayehu D. Evaluation of reporting bias in postmarketing risk assessment based on spontaneous reporting systems. Pharmaceut Med 2009;23:195-200.

7. Ghosh P, Dewanji A. Effect of reporting bias in the analysis of spontaneous reporting data. Pharm Stat 2015;14:20-5.

8. Hazell L, Shakir SA. Under-reporting of adverse drug reactions: a systematic review. Drug Saf 2006;29:385-96.

9. Trotter JP. Patient registries: a new gold standard for 'real world' research. Ochsner J 2002;4:211-4.

10. Tuven Health Analytics. Putting research data into your hands with the marketscan databases Truven Health Analytics. 2016. http:// truvenhealth.com/markets/life-sciences/products/data-tools/ marketscan-databases (accessed 5 Apr 2017).

11. Asgari MM, Wu JJ, Gelfand JM, et al. Validity of diagnostic codes and prevalence of psoriasis and psoriatic arthritis in a managed care population, 1996-2009. Pharmacoepidemiol Drug Saf 2013;22:842-9.
12. Metcalfe A, Neudam A, Forde S, et al. Case definitions for acute myocardial infarction in administrative databases and their impact on in-hospital mortality rates. Health Serv Res 2013;48:290-318.

13. Tirschwell DL, Longstreth WT. Validating administrative data in stroke research. Stroke 2002;33:2465-70.

14. Fiest KM, Jette N, Quan H, et al. Systematic review and assessment of validated case definitions for depression in administrative data. BMC Psychiatry 2014;14:289.

15. Nguyen-Khoa BA, Goehring EL, Alexander KA, et al. Risk of significant infection in rheumatoid arthritis patients switching anti-tumor necrosis factor- $\alpha$ drugs. Semin Arthritis Rheum 2012;42:119-26.

16. Kimball $A B$, Robinson $D$, Wu $\mathrm{Y}$, et al. Cardiovascular disease and risk factors among psoriasis patients in two US healthcare databases, 2001-2002. Dermatology 2008;217:27-37.

17. Winkelmayer WC, Schneeweiss S, Mogun $\mathrm{H}$, et al. Identification of individuals with CKD from Medicare claims data: a validation study. Am J Kidney Dis 2005;46:225-32.

18. Icen M, Crowson CS, McEvoy MT, et al. Potential misclassification of patients with psoriasis in electronic databases. J Am Acad Dermatol 2008;59:981-5

19. Shah K, Mellars L, Changolkar A, et al. Real-world burden of comorbidities in US patients with psoriasis. J Am Acad Dermatol 2017;77:287-92.

20. Han C, Robinson DW, Hackett MV, et al. Cardiovascular disease and risk factors in patients with rheumatoid arthritis, psoriatic arthritis and ankylosing spondylitis. J Rheumatol 2006;33:2167-72.

21. Feldman SR, Zhao Y, Shi L, et al. Economic and comorbidity burden among moderate-to-severe psoriasis patients with comorbid psoriatic arthritis. Arthritis Care Res 2015;67:708-17.

22. Husted JA, Thavaneswaran A, Chandran V, et al. Cardiovascular and other comorbidities in patients with psoriatic arthritis: a comparison with patients with psoriasis. Arthritis Care Res 2011;63:1729-35.

23. Centers for Disease Control and Prevention. National Diabetes Statistics Report. Atlanta, GA: Centers for Disease Control and Prevention. U.S. Department of Health and Human Services, 2017.

24. Sumary Health Statistics. Table A-1. Selected circulatory diseases among adults aged 18 and over, by selected characteristics: United States, 2015. Atlanta, GA: U.S. Department of Health and Human Services, Centers for Disease Control and Prevention, National Center for Health Statistics. https://ftp.cdc.gov/pub/Health Statistics/NCHS/NHIS/SHS/2015_SHS_Table_A-1.pdf (accessed 1 Nov 2017).

25. Ogden CL, Carroll MD, Fryar CD, et al. Prevalence of obesity among adults and youth: United States, 2011-2014. NCHS Data Brief 2015;219:1-8.

26. Carroll MD, Fryar CD, Kit BK. Total and high-density lipoprotein cholesterol in adults: United States, 2011-2014. NCHS Data Brief 2015;226:1-8.

27. Deng $Y$, Chang $C, L u Q$. The inflammatory response in psoriasis: a comprehensive review. Clin Rev Allergy Immunol 2016;50:377-89.

28. Armstrong AW, Harskamp CT, Armstrong EJ. Psoriasis and metabolic syndrome: a systematic review and meta-analysis of observational studies. J Am Acad Dermatol 2013;68:654-62

29. Ninomiya JK, L'Italien G, Criqui MH, et al. Association of the metabolic syndrome with history of myocardial infarction and stroke in the Third National Health and Nutrition Examination Survey. Circulation 2004;109:42-6.

30. Eder L, Chandran V, Cook R, et al. The risk of developing diabetes mellitus in patients with psoriatic arthritis: a cohort study. $J$ Rheumatol 2017;44:286-91.

31. Merola JF, Herrera V, Palmer JB, et al. Comorbidity burden and medication use between psoriatic arthritis patients with moderateto-severe psoriasis vs. those with minimal skin psoriasis in the US [poster FRI0580]. Presented at: The 2016 Annual European Congress of Rheumatology (EULAR). London, UK; 8-11 June 2016.

32. Bhole VM, Choi HK, Burns LC, et al. Differences in body mass index among individuals with PsA, psoriasis, RA and the general population. Rheumatology 2012;51:552-6.

33. Reynolds K, Go AS, Leong TK, et al. Trends in incidence of hospitalized acute myocardial infarction in the Cardiovascular Research Network (CVRN). Am J Med 2017;130:317-27.

34. Gladman DD, Ang M, Su L, et al. Cardiovascular morbidity in psoriatic arthritis. Ann Rheum Dis 2009;68:1131-5.

35. Eder L, Wu Y, Chandran V, et al. Incidence and predictors for cardiovascular events in patients with psoriatic arthritis. Ann Rheum Dis 2016;75:1680-6.

36. Armstrong AW, Brezinski EA, Follansbee MR, et al. Effects of biologic agents and other disease-modifying antirheumatic drugs 
on cardiovascular outcomes in psoriasis and psoriatic arthritis: a systematic review. Curr Pharm Des 2014;20:500-12.

37. Pratt LA, Brody DJ. Depression in the U.S. household population, 2009-2012. NCHS Data Brief 2014;172:1-8.

38. McDonough E, Ayearst R, Eder L, et al. Depression and anxiety in psoriatic disease: prevalence and associated factors. $J$ Rheumatol 2014;41:887-96.

39. Rohekar S, Tom BD, Hassa A, et al. Prevalence of malignancy in psoriatic arthritis. Arthritis Rheum 2008;58:82-7.

40. Gross RL, Schwartzman-Morris JS, Krathen M, et al. A comparison of the malignancy incidence among patients with psoriatic arthritis and patients with rheumatoid arthritis in a large US cohort. Arthritis Rheumatol 2014;66:1472-81.
41. Cancer of Any Site. Statistics at a glance: National Institute of Health, surveillance, epidemiology, and end results program. 2017. https://seer.cancer.gov/statfacts/html/all.html (accessed 1 Nov 2017)

42. Brikman S, Furer V, Wollman J, et al. The effect of the presence of Fibromyalgia on common clinical disease activity indices in patients with psoriatic arthritis: a cross-sectional study. J Rheumatol 2016;43:1749-54.

43. Lim JL, Stern RS. High levels of ultraviolet B exposure increase the risk of non-melanoma skin cancer in psoralen and ultraviolet A-treated patients. J Invest Dermatol 2005;124:505-13.

44. Klabunde CN, Warren JL, Legler JM. Assessing comorbidity using claims data: an overview. Med Care 2002;40:26-35. 